\title{
Insulin adherence and persistence among Chinese patients with type 2 diabetes: a retrospective database analysis
}

This article was published in the following Dove Press journal:

Patient Preference and Adherence

13 February 2017

Number of times this article has been viewed

\author{
Xiaoning $\mathrm{He}^{1}$ \\ Liming Chen ${ }^{2}$ \\ Ke Wang ${ }^{3}$ \\ Haiya $W_{u^{3}}$ \\ jing $\mathrm{Wu}^{\prime}$
}

'Department of Health Pharmacy

and Administration, School of

Pharmaceutical Science and

Technology, Tianjin University,

Tianjin, ${ }^{2}$ Department of Metabolic

Disease, Tianjin Medical University

Metabolic Diseases Hospital, Tianjin,

${ }^{3}$ Medical Department, Lilly Suzhou

Pharmaceutical Company, Ltd.,

Shanghai, People's Republic of China
Correspondence: Jing Wu

School of Pharmaceutical Science

and Technology, Tianjin University,

No 92 Weijin Road, Nankai District,

Tianjin 300072, People's Republic

of China

Tel +8622 27405176

Fax +86 228740 I830

Email jingwu@tju.edu.cn
Objective: To assess adherence and persistence to insulin therapy and identify its associated factors among Chinese insulin-naïve patients with type 2 diabetes (T2D).

Methods: Tianjin Urban Employee Basic Medical Insurance claims database was used (2008-2011). Adult patients with T2D who initiated insulin therapy during January 2009 through December 2010 and were continuously enrolled for 12 months pre-(baseline) and 12 months post-initiation (follow-up) were included. Patients who had a $\geq 80 \%$ medication possession ratio were deemed adherent, while patients who had no gaps of $\geq 90$ days in insulin therapy were deemed persistent. Associated factors of insulin adherence and persistence were detected by univariate and multivariate analyses.

Results: A total of 24,192 patients were included; the patients had a mean age of 58.9 years, with $49.5 \%$ being female. About $51.9 \%$ of the patients had human insulin as initiation therapy, while $39.1 \%$ were initiated with insulin analog and $9.0 \%$ with animal-derived insulin. Premixed insulin $(77.3 \%)$ was prescribed most often in comparison with basal (11.8\%) and prandial (10.9\%) insulin. Only $30.9 \%$ of patients were adherent, and the mean (standard deviation) medication possession ratio was $0.499(0.361)$. About $53.0 \%$ of patients persisted insulin therapy during follow-up, and the mean time to nonpersistence was 230.3 (145.5) days. Patients initiated with analog were more likely to be adherent (adjusted odds ratio: 1.07, $P=0.036$ ) and persistent (adjusted hazard ratio: $0.88, P<0.001$ ) compared with those initiated with human insulin. Patients initiation with basal insulin had lower adherence relative to premixed (adjusted odds ratio: $0.79, P<0.001)$. Patients comorbid with hypertension or dyslipidemia, initiated with prandial insulin, and with baseline severe hypoglycemic events were more likely to be nonadherent/nonpersistent.

Conclusion: The insulin adherence and persistence among Chinese patients with T2D are generally poor. Initiation with insulin analog or premixed insulin may result in better adherence/ persistence to insulin therapy.

Keywords: type 2 diabetes mellitus, insulin, adherence, persistence

\section{Background}

Diabetes is one of the major public health issues around the world. More than 415 million individuals had diabetes worldwide in $2015 .{ }^{1}$ With 109.6 million of its people affected, China ranks number one in diabetes prevalence due to its aging population and rising obesity rates. ${ }^{1,2}$ Uncontrolled blood glucose leads to severe microvascular and macrovascular complications including chronic kidney disease, retinopathy, neuropathy, stroke, and myocardial infarction. ${ }^{3,4}$ Diabetes places a heavy burden on the health care system and national economy, and the total cost 
of treating its complications greatly exceeded the cost of treatment itself. According to the International Diabetes Federation, the disease incurred an overall economic burden of $\$ 612$ billion in $2014 .{ }^{1}$ More than $90 \%$ of individuals with diabetes have type 2 diabetes (T2D), which is characterized by high blood glucose in the context of insulin resistance and/or insulin deficiency. ${ }^{5,6}$ Long-term glycemic control is fundamental to the management of diabetes and has been shown to reduce both microvascular and macrovascular complications. $^{7,8}$

Insulin is the most effective glucose-lowering agent and is a key component of effective diabetes management over the course of diabetes. ${ }^{9,10}$ While the current treatment guidelines for T2D suggest a stepwise approach to drug therapy starting with metformin and lifestyle modification, many patients eventually require insulin, either alone or in combination with other agents, to maintain glycemic control. ${ }^{11,12}$ In China, as many as $48.8 \%$ of patients with T2D use insulin to treat this disease. ${ }^{13}$ However, as injectable insulin therapy is associated with negative perceptions for patients, and they usually cannot feel consequences of skipping doses immediately, adherence/persistence to insulin therapy among diabetic patients can be a particularly challenging issue. ${ }^{14}$

The full clinical benefit of insulin treatment cannot be achieved without optimal adherence/persistence. ${ }^{15}$ In order to identify potential solutions, it is important to estimate insulin adherence/persistence among diabetic patients and understand its influencing factors quantitatively.

Several studies in developed countries have assessed levels of adherence/persistence to prescribed insulin. ${ }^{16-19}$ A systematic review by $\mathrm{Cramer}^{20}$ reported that adherence rates to insulin were $62 \%-64 \%$ among diabetic patients in developed countries and that $80 \%$ of patients persisted with insulin treatment for 24 months. Studies aimed to detect associated factors of insulin adherence/persistence were also conducted in developed countries, ${ }^{16-19}$ and factors such as age, gender, insulin types, and administration mode were found to be associated with nonadherence. ${ }^{14,19,21,22}$ However, no large-scale quantitative studies have been conducted in China, where diabetes care, treatment pattern, and patient profile are largely different. ${ }^{23}$ As a result, insulin adherence/ persistence status and its related factors are still unclear in this developing country. ${ }^{24-26}$

Our study aimed to estimate insulin adherence and persistence to insulin therapy among insulin-naïve Chinese patients with T2D and to investigate associated factors, aiming to provide information for the better management of this prevalent disease.

\section{Methods}

The claims data of Urban Employee Basic Medical Insurance (UEBMI) of the city of Tianjin (2008-2011) were used, through a formal request to Municipal Human Resources and Social Security Bureau in Tianjin for research purposes. By 2011, the Tianjin UEBMI system covered about 4.84 million enrollees, which represented $48.6 \%$ of registered Tianjin residents. ${ }^{27}$ Of them, $30 \%$ of all the enrollees were used as our analytical sample, chosen by random sampling. Data provided included demographic characteristics, medical claims of inpatient and outpatient service, prescription claims (quantity, strength, date of prescription, etc), and related medical and medication costs. The Safety and Ethics Committee of School of Pharmaceutical Science and Technology in Tianjin University waived the requirement of ethical approval for the current study.

Adult patients with T2D who had at least one initial prescription claim for insulin from January 1, 2009 to December 31, 2010, and had continuous enrollment for the 12 months pre-(baseline) and 12 months post-initiation (follow-up) period were included. The date of first insulin prescription was identified as the patient's index date. Patients with T2D were identified if they had at least one of following conditions in baseline period through 30 days after the index date: 1 ) $\geq 2$ prescriptions of oral antidiabetic medications (OADs); 2) $\geq 1$ inpatient claim(s) with a diagnosis of T2D (ICD-10 code E11.xx supplemented by the Chinese descriptions); and 3 ) $\geq 2$ outpatient claims ( $\geq 30$ days apart) with diagnoses of T2D.

Patients who had any prescription of insulin at baseline (not insulin-naïve) or had more than one type of insulin (eg, human and analog) at index date were excluded. Patients who had any diagnosis of gestational diabetes (ICD-10 code O24.xx) or type 1 diabetes (ICD-10 code E11.xx) anytime during the observation period were also excluded. Patients who initiated insulin therapy during a hospitalization but had no insulin prescription after discharge were also excluded, because they may have required insulin for acute hyperglycemic events during hospitalization, and so they do not reflect our target patients.

Patient demographics included age, gender, and working status. Index insulin characteristics including insulin type (human, analog, or animal-derived insulin), action profile (prandial, basal, or premixed), and administration (pen or vial/syringe) were also recorded. Baseline clinical characteristics including a count of hemoglobin $\mathrm{A}_{1 \mathrm{c}}\left(\mathrm{HbA}_{1 \mathrm{c}}\right)$ tests, claims-based hypoglycemic events, Charlson Comorbidity Index (CCI), ${ }^{28}$ comorbidities and complications relating to 
diabetes mellitus (hypertension, dyslipidemia, retinopathy, neuropathy, and nephropathy), ${ }^{22,29}$ and a count of OAD classes were recorded and calculated. Claims-based hypoglycemic events were identified through a diagnosis associated with hypoglycemia (ICD-10 code E16.0-16.2) supplemented by the Chinese descriptions. The number of OAD classes was calculated through claims for metformin, sulfonylureas, meglitinides, thiazolidinediones, and $\alpha$-glucosidase inhibitors. The baseline health care resource use for all-cause hospitalizations and baseline all-cause direct medical costs were also estimated.

Medication possession ratio (MPR), which is calculated as the total days supply of all insulin prescriptions divided by 365 follow-up days in our study, was used to estimate patients' adherence to insulin therapy. Days during a hospitalization with insulin prescriptions were counted as days with insulin available. Days for a prescription during an outpatient visit were calculated by the dispensed quantity and strength. Overlapping days of insulin therapy between two refills were excluded. Patients with MPR values less than $80 \%$ were deemed nonadherent, which is the most commonly used cutoff value in studies of adherence to insulin therapy as well as analyses for other medications/chronic conditions. ${ }^{18,20,30,31}$

Persistence was defined as the absence of $\geq 90$ days gaps between refills during the follow-up. Patients were deemed to be nonpersistent if they did not refill the insulin therapy within 90 days after the previous fill had run out. Persistence duration, ie, time to discontinuation/nonpersistence, was calculated as the number of days between the initiation (index date) to the date that the last fill had ran out and was truncated to a maximum of 365 days. The criterion of 90 days was chosen after consultation with experienced endocrinologists, and this criterion was also consistent with previous literature measuring insulin persistence. ${ }^{17,32}$

Descriptive analyses of patients' demographic and clinical characteristics were conducted. The adherence and persistence to insulin therapy were estimated for the total cohort and subgroups divided by gender, age, and index insulin types. Differences between subgroups were tested for statistical significance using Student's $t$-tests or analysis of variance (ANOVA) when appropriate. A Kaplan-Meier curve was used to examine the time to discontinuation/nonpersistence among all patients.

Unadjusted and adjusted odds ratios (ORs) were calculated to identify the associated factors of adherence, using univariate and multivariate logistic regression models, respectively. Similarly, univariate and multivariate Cox proportional hazards models were used to identify the associated factors of persistence (time to discontinuation/nonpersistence) with insulin therapy, and the results are presented as hazard ratios. Demographics (age, gender, and working status), characteristics of index insulin (source type, action profile), baseline clinical factors (count of $\mathrm{HbA}_{1 \mathrm{c}}$ tests, claims-based hypoglycemic events, CCI, comorbidities and complications, and count of OAD classes), baseline health care use for hospitalization, and log-transformed costs were included as potential factors in the multivariate analysis. The administration mode of insulin was removed from the multivariate analysis due to its collinearity with insulin type and action profile (eg, all animal-derived insulin was administered by vial).

Statistics analysis was conducted using STATA 12.0 (StataCorp LP, College Station, TX, USA). The significance level was set as two-sided $\alpha<0.05$. All costs in RMB were converted to USD with an exchange rate of 6.83 in $2010 .{ }^{33}$

\section{Results \\ Baseline characteristics}

A total of 24,192 eligible patients were included, and they had a mean (standard deviation [SD]) age of 58.9 (11.5), with $49.5 \%$ being female and $69.6 \%$ retired (Table 1 ). About $51.9 \%$ of the patients initiated therapy with human insulin, and the corresponding estimates for initiation with insulin analog and animal-derived insulin were $39.1 \%$ and $9.0 \%$, respectively. As many as $77.3 \%$ of the patients had premixed insulin at their index date, while only $11.8 \%$ of the patients were initiated with basal insulin. Most patients were prescribed insulin with a pen $(89.2 \%)$ rather than a vial $(10.8 \%)$.

The mean number of baseline $\mathrm{HbA}_{1 \mathrm{c}}$ tests among the total cohort is relatively low (0.34), and only $0.8 \%$ of the patients were found to have baseline hypoglycemic events. The mean (SD) CCI among the total cohort was 1.98 (1.44), with $49.8 \%$ comorbid with hypertension and $26.2 \%$ comorbid with dyslipidemia. Patients also had high prevalence of microvascular complications including retinopathy (16.8\%), neuropathy (23.1\%), and nephropathy (17.2\%). Patients were using 2.22 classes of OADs at baseline on average, with $67.5 \%$ of patients on $\alpha$-glucosidase inhibitors, $51.9 \%$ on meglitinides, and $42.1 \%$ on metformin. During baseline, $22.6 \%$ of the patients experienced $\geq 1$ hospitalizations, and the average baseline total cost was $\$ 845$.

\section{Unadjusted adherence and persistence}

The total cohort had a mean (SD) MPR of 0.499 (0.361) during the 12-month follow-up period (Table 2). About 30.9\% 
Table I Baseline characteristics of the total cohort $(\mathrm{N}=24,192)$

\begin{tabular}{|c|c|}
\hline Baseline characteristics & $\begin{array}{l}\text { Total cohort } \\
\mathbf{N}=24,192\end{array}$ \\
\hline \multicolumn{2}{|l|}{ Demographic characteristics } \\
\hline Mean age, mean (SD) & $58.9(11.5)$ \\
\hline \multicolumn{2}{|l|}{ Age group, $\mathrm{n}(\%)$} \\
\hline$<40$ & $1,013(4.2)$ \\
\hline [40-49] & $3,574(14.8)$ \\
\hline [50-59] & $9,105(37.6)$ \\
\hline$[60-69]$ & $5,735(23.7)$ \\
\hline$\geq 70$ & $4,765(19.7)$ \\
\hline Female, n (\%) & II,976 (49.5) \\
\hline Retired, n (\%) & $16,833(69.6)$ \\
\hline \multicolumn{2}{|l|}{ Index insulin source, n (\%) } \\
\hline Human insulin & I2,547 (5।.9) \\
\hline Insulin analog & $9,461(39.1)$ \\
\hline Animal-derived insulin & $2,184(9.0)$ \\
\hline \multicolumn{2}{|l|}{ Index insulin action profile, $\mathrm{n}(\%)$} \\
\hline Prandial insulin & $2,628(10.9)$ \\
\hline Basal insulin & $2,865(I I .8)$ \\
\hline Premixed insulin & $18,699(77.3)$ \\
\hline \multicolumn{2}{|l|}{ Index insulin administration, $\mathrm{n}(\%)$} \\
\hline Vials and syringes & $2,606(10.8)$ \\
\hline Pens & $21,586(89.2)$ \\
\hline Count of $A_{I c}$ tests, mean (SD) & $0.34(0.64)$ \\
\hline Any claims-based hypoglycemic events, $n(\%)$ & $191(0.8)$ \\
\hline \multicolumn{2}{|l|}{ Comorbidities and complications, $n(\%)$} \\
\hline $\mathrm{CCl}$, mean (SD) & $1.98(1.44)$ \\
\hline Hypertension & $12,039(49.8)$ \\
\hline Dyslipidemia & $6,340(26.2)$ \\
\hline Retinopathy & $4,057(16.8)$ \\
\hline Neuropathy & $5,579(23.1)$ \\
\hline Nephropathy & $4,167(17.2)$ \\
\hline Count of unique $O A D$ drug classes, mean (SD) & $2.22(1.30)$ \\
\hline Metformin & $10,190(42.1)$ \\
\hline Sulfonylureas & $8,268(34.2)$ \\
\hline Meglitinides & $|2,55|(5 \mid .9)$ \\
\hline Thiazolidinediones & $6,458(26.7)$ \\
\hline$\alpha$-Glucosidase inhibitors & $16,324(67.5)$ \\
\hline Any hospitalizations, n (\%) & $5,477(22.6)$ \\
\hline Direct medical cost $(\$)$, mean (SD) & $845(1,493)$ \\
\hline
\end{tabular}

Abbreviations: SD, standard deviation; $\mathrm{CCl}$, Charlson Comorbidity Index; OAD, oral antidiabetic medication.

$(\mathrm{N}=7,486)$ of them were adherent with a MPR of $\geq 0.8$ in follow-up. Relative to the patients aged $<40$ years (mean MPR $=0.399$ ), adherence increased gradually with older patients, reaching a peak at age $50-55$ years (MPR $=0.571$ ), then decreased for patients aged older than 55. Patients administered insulin through insulin pens had a higher adherence compared with those using vials and syringes $(0.524$ vs $0.295, P<0.001)$.

As presented in Figure 1, the Kaplan-Meier survival curve examines the percentage of persistent patients with the days from the index date increasing. Discontinuation occurred relatively early after initiation of insulin, with approximately $14.1 \%$ of patients discontinuing in the first month and 29\% discontinuing in the first 3 months, after which the cumulative probability increased steadily over the follow-up period. Only 53\% were persistent during the follow-up period. The mean (SD) time to nonpersistence among the total cohort was 230.3 (145.5) days (Table 2). Consistent with the findings from the unadjusted adherence, the unadjusted persistence, demonstrated by the time to nonpersistence, was numerically higher among patients aged between 50 and 55 and patients using insulin pens.

\section{Factors associated with adherence}

The MPR-based adherent $(\mathrm{N}=7,486)$ and nonadherent $(\mathrm{N}=16,706)$ patient subgroups differed on most of the baseline characteristics, and the results in univariate and multivariate analyses were similar regarding most of the factors (Table 3 ).

Patients aged between 40 and 69 years were more likely to be adherent compared with those $\geq 70$ years (all $P<0.001$ ). Patients who received initial treatment with analog insulin, compared with human insulin, were more likely to be adherent (adjusted OR [95\% CI]: OR [95\% CI]: 1.07 [1.00-1.14], $P=0.036$ ), while those who received initial treatment with animal-derived insulin were significantly less likely to be adherent (adjusted OR [95\% CI]: 0.46 [0.36-0.59], $P<0.001)$. In comparison with premixed insulin, initial treatment with prandial insulin (adjusted OR [95\% CI]: 0.55 [0.45-0.68], $P<0.001$ ) or basal insulin (adjusted OR [95\% $\mathrm{CI}]: 0.79$ [0.72-0.87], $P<0.001)$ was associated with poorer adherence. Baseline count of $\mathrm{HbA}_{1 \mathrm{c}}$ tests (adjusted OR [95\% CI]: 1.19 [1.13-1.25], $P<0.001)$ and count of unique OAD classes (adjusted OR [95\% CI]: 1.16 [1.13-1.19], $P<0.001$ ) were positively associated with adherence. Patients who had baseline hypoglycemia events were statistically less likely to be adherent (adjusted OR [95\% CI]: 0.62 [0.42-0.91], $P=0.015)$. Patients with a higher $\mathrm{CCI}$, or having had comorbidities including hypertension and dyslipidemia, had a lower likelihood of being adherent (all $P<0.001$ ). A comorbid diagnosis of neuropathy or nephropathy was related to a significantly higher likelihood of adherence (all $P<0.001$ ).

\section{Factors associated with persistence}

Table 4 presents the results of unadjusted and adjusted persistence analysis using Cox regressions, and the results were similar to those of the adherence analysis. The likelihood of being persistent was higher for patients aged 40-69 years (all hazard ratio [HR] $<1, P<0.001$ ), patients initiated with analog (vs human insulin; adjusted HR [95\% CI]: 0.88 [0.85-0.92], $P<0.001)$, patients with higher baseline count 
Table 2 Unadjusted adherence and persistence in total cohort and subgroups

\begin{tabular}{|c|c|c|c|c|c|}
\hline \multirow[t]{2}{*}{ Subgroups } & & \multicolumn{2}{|l|}{ MPR } & \multicolumn{2}{|c|}{ Time to nonpersistence } \\
\hline & & Mean (SD) & $P$-value & Mean (SD) & $P$-value \\
\hline Total cohort & $(\mathrm{N}=24,192)$ & $0.499(0.361)$ & & $230.3(145.5)$ & \\
\hline Gender subgroup & & & $0.097^{a}$ & & $0.540^{\mathrm{a}}$ \\
\hline Male & $(\mathrm{N}=12,216)$ & $0.495(0.359)$ & & $230.9(145.4)$ & \\
\hline Female & $(\mathrm{N}=11,976)$ & $0.503(0.364)$ & & $229.8(145.5)$ & \\
\hline Age subgroup & & & $<0.00 \mathrm{I}^{\mathrm{b}}$ & & $0.775^{b}$ \\
\hline$<40$ & $(\mathrm{~N}=|, 0| 3)$ & $0.399(0.348)$ & & $185.0(\mid 49.2)$ & \\
\hline [40-44] & $(\mathrm{N}=885)$ & $0.485(0.358)$ & & $220.0(146.8)$ & \\
\hline [45-49] & $(\mathrm{N}=2,689)$ & $0.555(0.364)$ & & $243.1(144.3)$ & \\
\hline$[50-54]$ & $(\mathrm{N}=4,392)$ & $0.571(0.364)$ & & $249.7(142.3)$ & \\
\hline [55-59] & $(\mathrm{N}=4,7 \mid 3)$ & $0.546(0.362)$ & & $243.7(143.6)$ & \\
\hline$[60-64]$ & $(\mathrm{N}=3,432)$ & $0.513(0.357)$ & & $235.5(144.8)$ & \\
\hline [65-69] & $(\mathrm{N}=2,303)$ & $0.466(0.348)$ & & $224.1(144.4)$ & \\
\hline [70-74] & $(\mathrm{N}=2,169)$ & $0.4 I 4(0.34 I)$ & & $214.2(\mid 44.1)$ & \\
\hline [75-79] & $(\mathrm{N}=\mathrm{I}, 597)$ & $0.382(0.335)$ & & $201.5(144.8)$ & \\
\hline$\geq 80$ & $(\mathrm{~N}=999)$ & $0.328(0.319)$ & & $\mid 80.4(|4| .3)$ & \\
\hline Index insulin source & & & $<0.00 \mathrm{I}^{\mathrm{b}}$ & & $<0.00 I^{b}$ \\
\hline Human & $(\mathrm{N}=12,547)$ & $0.509(0.365)$ & & $225.8(146.8)$ & \\
\hline Analog & $(\mathrm{N}=9,46 \mathrm{I})$ & $0.540(0.356)$ & & $242.9(144.4)$ & \\
\hline Animal & $(\mathrm{N}=2,184)$ & $0.269(0.270)$ & & $202.2(136.3)$ & \\
\hline Index insulin action profile & & & $<0.00 \mathrm{I}^{\mathrm{b}}$ & & $<0.00 \mathrm{I}^{\mathrm{b}}$ \\
\hline Mealtime & $(\mathrm{N}=2,628)$ & $0.294(0.287)$ & & $205.8(137.3)$ & \\
\hline Basal & $(\mathrm{N}=2,865)$ & $0.522(0.343)$ & & $239.0(143.8)$ & \\
\hline Premixed & $(\mathrm{N}=18,699)$ & $0.524(0.364)$ & & $232.5(146.5)$ & \\
\hline Index insulin administration & & & $<0.00 \mathrm{I}^{\mathrm{a}}$ & & $<0.00 I^{a}$ \\
\hline Vials and syringes & $(\mathrm{N}=2,606)$ & $0.295(0.287)$ & & $207.7(137.4)$ & \\
\hline Pens & $(\mathrm{N}=21,586)$ & $0.524(0.362)$ & & $233.1(146.2)$ & \\
\hline
\end{tabular}

Notes: aStudent's t-test, 'ANOVA.

Abbreviations: MPR, medication possession ratio; SD, standard deviation; ANOVA, analysis of variance.

of $\mathrm{HbA}_{1 \mathrm{c}}$ in tests (adjusted HR [95\% CI]: 0.81 [0.78-0.84], $P<0.001$ ), patients with higher unique OAD classes (adjusted HR [95\% CI]: 0.86 [0.84-0.87], $P<0.001$ ), and patients with comorbid with microvascular complications including neuropathy and nephropathy (all HR $<1, P<0.001$ ). The likelihood of being persistent was lower for those

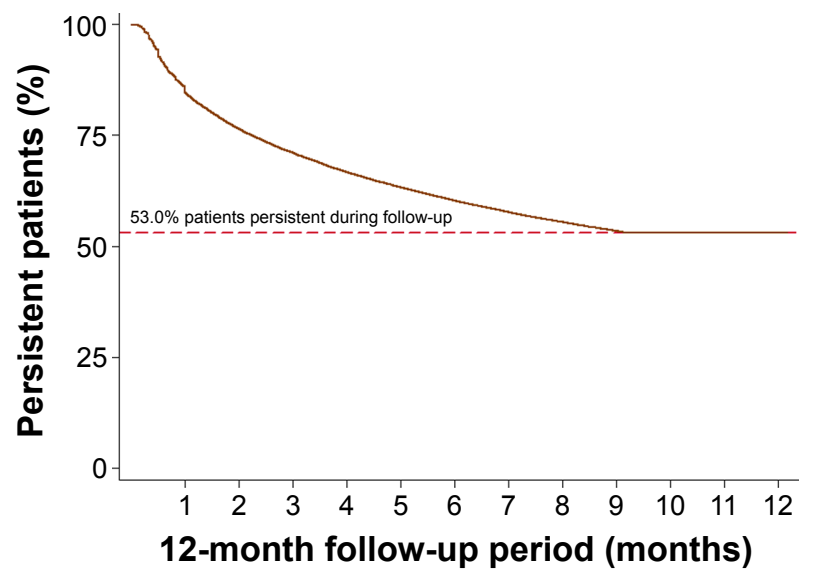

Figure I Kaplan-Meier curve for insulin persistence during follow-up period. who initiated with prandial insulin (vs premixed; adjusted HR [95\% CI]: 1.24 [1.09-1.40], $P<0.001)$, those having baseline hypoglycemia events (adjusted HR [95\% CI]: 1.44 [1.20-1.74], $P<0.001$ ), and those with comorbid hypertension (adjusted HR [95\% CI]: 1.80 [1.71-1.88], $P<0.001$ ) or dyslipidemia (adjusted HR [95\% CI]: 1.19 [1.14-1.25], $P<0.001)$.

\section{Discussion}

To the best of our knowledge, the current study is the first to quantitatively evaluate adherence and persistence to insulin treatments in China. We found that insulin adherence and persistence are generally poor among insulin-naïve patients with T2D in China. Only 30.9\% individuals were adherent during the first year following insulin initiation, and only $53 \%$ were persistent at 12 months. On average, patients discontinued insulin treatment 230.3 days after the initiation. Patients aged between 40 and 69 years, initiated therapy with analog instead of human insulin, premixed instead of prandial insulin, had more baseline $\mathrm{HbA}_{1 \mathrm{c}}$ tests or more 
Table 3 Unadjusted and adjusted characteristics for insulin adherent and nonadherent cohorts during I2-month follow-up period

\begin{tabular}{|c|c|c|c|c|c|c|c|c|}
\hline \multirow[t]{2}{*}{ Patient characteristics } & \multirow{2}{*}{$\begin{array}{l}\text { Adherent } \\
\mathrm{N}=7,486\end{array}$} & \multirow{2}{*}{$\begin{array}{l}\text { Nonadherent } \\
N=16,706\end{array}$} & \multicolumn{3}{|c|}{ Unadjusted analysis } & \multicolumn{3}{|c|}{ Adjusted analysis } \\
\hline & & & OR & $95 \% \mathrm{Cl}$ & $P$-value & OR & $95 \% \mathrm{Cl}$ & $P$-value \\
\hline \multicolumn{9}{|l|}{ Age group, n (\%) } \\
\hline$<40$ & $224(3.0)$ & $789(4.7)$ & 1.24 & $1.05-1.47$ & 0.009 & 1.13 & $0.93-1.37$ & 0.224 \\
\hline [40-49] & $1,263(16.9)$ & $2,3 \mid I(\mid 3.8)$ & 2.40 & $2.17-2.65$ & $<0.001$ & 2.09 & I.83-2.40 & $<0.001$ \\
\hline [50-59] & $3,458(46.2)$ & $5,647(33.8)$ & 2.68 & $2.47-2.92$ & $<0.001$ & 2.07 & $1.88-2.28$ & $<0.001$ \\
\hline [60-69] & I,656 (22.1) & $4,079(24.4)$ & 1.78 & $1.62-1.95$ & $<0.001$ & 1.41 & $1.28-1.56$ & $<0.001$ \\
\hline$\geq 70$ & $885(11.8)$ & $3,880(23.2)$ & I (reference) & & & I (reference) & & \\
\hline Female, n (\%) & $3,807(50.9)$ & $8,169(48.9)$ & 1.08 & $1.02-1.14$ & 0.005 & 0.95 & $0.89-1.01$ & 0.100 \\
\hline Retired, n (\%) & $5,087(68.0)$ & II,746 (70.3) & 0.90 & $0.84-0.95$ & $<0.001$ & 1.32 & $1.20-1.45$ & $<0.001$ \\
\hline \multicolumn{9}{|l|}{ Index insulin source, n (\%) } \\
\hline Human insulin & $4,102(54.8)$ & $8,445(50.6)$ & I (reference) & & & I (reference) & & \\
\hline Insulin analog & $3,215(42.9)$ & $6,246(37.4)$ & 1.06 & $1.00-1.12$ & 0.045 & 1.07 & $1.00-1.14$ & 0.036 \\
\hline Animal-derived insulin & $169(2.3)$ & $2,015(12.1)$ & 0.17 & $0.15-0.20$ & $<0.001$ & 0.46 & $0.36-0.59$ & $<0.001$ \\
\hline \multicolumn{9}{|l|}{ Index insulin action profile, n (\%) } \\
\hline Prandial insulin & $264(3.5)$ & $2,364(\mid 4.2)$ & 0.22 & $0.19-0.25$ & $<0.001$ & 0.55 & $0.45-0.68$ & $<0.001$ \\
\hline Basal insulin & $870(11.6)$ & $1,995(11.9)$ & 0.85 & $0.78-0.92$ & $<0.001$ & 0.79 & $0.72-0.87$ & $<0.001$ \\
\hline Premixed insulin & $6,352(84.9)$ & I2,347 (73.9) & I (reference) & & & I (reference) & & \\
\hline Count of $A_{I c}$ tests, mean (SD) & $0.38(0.66)$ & $0.32(0.63)$ & 1.16 & $1.11-1.20$ & $<0.001$ & 1.19 & $1.13-1.25$ & $<0.001$ \\
\hline Any claims-based hypoglycemic events, n (\%) & $35(0.5)$ & $166(1.0)$ & 0.47 & $0.32-0.67$ & $<0.001$ & 0.62 & $0.42-0.91$ & 0.015 \\
\hline \multicolumn{9}{|l|}{ Comorbidities and complications } \\
\hline $\mathrm{CCl}$, mean $(\mathrm{SD})$ & $1.64(1.21)$ & $2.13(1.51)$ & 0.75 & $0.73-0.76$ & $<0.001$ & 0.93 & $0.91-0.96$ & $<0.001$ \\
\hline Hypertension, n (\%) & $2,4 I I(32.2)$ & $9,628(57.6)$ & 0.35 & $0.33-0.37$ & $<0.001$ & 0.47 & $0.44-0.50$ & $<0.001$ \\
\hline Dyslipidemia, n (\%) & I,378 (I8.4) & 4,967 (29.7) & 0.53 & $0.50-0.57$ & $<0.001$ & 0.74 & $0.68-0.80$ & $<0.001$ \\
\hline Retinopathy, n (\%) & $1,268(16.9)$ & $2,789(16.7)$ & 1.02 & $0.95-1.09$ & 0.639 & 0.98 & $0.91-1.07$ & 0.698 \\
\hline Neuropathy, n (\%) & $2,146(28.7)$ & $3,433(20.5)$ & 1.55 & $1.46-1.65$ & $<0.001$ & 1.33 & $1.24-1.43$ & $<0.001$ \\
\hline Nephropathy, n (\%) & I,653 (22.I) & $2,514(15.0)$ & 1.60 & $|.49-| .7 \mid$ & $<0.001$ & 1.40 & $1.30-1.52$ & $<0.001$ \\
\hline Count of unique OAD drug classes, mean (SD) & $2.45(1.28)$ & $2.12(1.29)$ & 1.21 & $1.18-1.24$ & $<0.001$ & 1.16 & $1.13-1.19$ & $<0.001$ \\
\hline Any hospitalizations, n (\%) & $\mathrm{I}, 127(15.1)$ & $4,350(26.0)$ & 0.50 & $0.47-0.54$ & $<0.001$ & 0.94 & $0.86-1.02$ & 0.148 \\
\hline Direct medical cost $(\$)$, mean (SD) & $753(1,430)$ & $887(1,519)$ & 0.96 & $0.94-0.97$ & $<0.001$ & 0.97 & $0.95-0.99$ & 0.006 \\
\hline
\end{tabular}

Note: $O R>I$ indicates that patients were more likely to be adherent than the reference group.

Abbreviations: SD, standard deviation; OR, odds ratio; $\mathrm{Cl}$, confidence interval; $\mathrm{CCl}$, Charlson Comorbidity Index; OAD, oral antidiabetic medication.

classes of OADs, and were comorbid with microvascular complications (except retinopathy) were more likely to be adherent/persistent. Baseline claims-based hypoglycemic events and comorbidity with hypertension or dyslipidemia were found to be risk factors for both poor adherence and persistence, while early age $(<40)$ and being female were found to be risk factors for poor persistence only.

The mean adherence rate among Chinese insulin users in our analysis was 0.499 (ie, 49.9\%), lower than the results found in developed countries such as the US (range $62 \%-74.5 \%$ ) and developing countries such as Nigeria (77\%). ${ }^{16,20,34}$ The study also found that early discontinuation was common among Chinese insulin initiators, similar to previous findings from the other countries. ${ }^{19}$ The relatively low adherence and high early discontinuation rate suggested that adherence and persistence to insulin therapy are still poor in China among patients with T2D, far from optimal for successful disease management. The results also highlighted the urgent need for effective strategies to increase Chinese patients' compliance to medication. Published studies revealed that diabetes self-management education programs, especially better diabetes education, could help improve medication adherence, glycemic control, and diabetes self-management among T2D patients. ${ }^{21,35,36}$ The poor rates of insulin adherence presented in our study suggest that considerable work is clearly needed in China.

The risk factor analysis of this study may provide clues for future focuses or possible interventions on this matter. Our study showed that patients aged between 40 and 69 years were more likely to adhere/persist to their insulin treatments than those aged $>70$ years, whereas patients younger than 40 had even poorer persistence. This is in line with a retrospective study from Bonafede et a $1^{17}$ where patients $<35$ years and $>65$ years were found less likely to be persistent. These results may explain the mixed findings in previous studies that treated age as a continuous variable. ${ }^{16,18,22,34,37,38}$ 
Table 4 Unadjusted and adjusted characteristics for insulin persistent and nonpersistent cohorts during I2-month follow-up period

\begin{tabular}{|c|c|c|c|c|c|c|c|c|}
\hline \multirow[t]{2}{*}{ Patient characteristics } & \multirow{2}{*}{$\begin{array}{l}\text { Persistent } \\
N=12,823\end{array}$} & \multirow{2}{*}{$\begin{array}{l}\text { Nonpersistent } \\
\mathrm{N}=1 \mathrm{I}, 369\end{array}$} & \multicolumn{3}{|c|}{ Unadjusted analysis } & \multicolumn{3}{|c|}{ Adjusted analysis } \\
\hline & & & HR & $95 \% \mathrm{Cl}$ & $P$-value & HR & $95 \% \mathrm{Cl}$ & $P$-value \\
\hline \multicolumn{9}{|l|}{ Age group, n (\%) } \\
\hline$<40$ & $397(3.1)$ & $616(5.4)$ & 1.16 & $1.07-1.27$ & 0.001 & 1.24 & I.II-I.39 & $<0.001$ \\
\hline [40-49] & $1,990(15.5)$ & $\mathrm{I}, 584(13.9)$ & 0.71 & $0.67-0.76$ & $<0.00 \mathrm{I}$ & 0.80 & $0.74-0.88$ & $<0.001$ \\
\hline [50-59] & $5,329(41.6)$ & $3,776(33.2)$ & 0.65 & $0.62-0.68$ & $<0.001$ & 0.77 & $0.73-0.82$ & $<0.001$ \\
\hline [60-69] & $3,047(23.8)$ & $2,688(23.6)$ & 0.76 & $0.72-0.81$ & $<0.001$ & 0.89 & $0.84-0.94$ & $<0.001$ \\
\hline$\geq 70$ & $2,060(16.1)$ & $2,705(23.8)$ & I (reference) & & & I (reference) & & \\
\hline Female, n (\%) & $6,319(49.3)$ & $5,657(49.8)$ & 1.01 & $0.98-1.05$ & 0.463 & 1.07 & $1.02-1.11$ & 0.002 \\
\hline Retired, n (\%) & $8,881(69.3)$ & $7,952(69.9)$ & 1.01 & $0.97-1.06$ & 0.509 & 0.86 & $0.81-0.92$ & $<0.001$ \\
\hline \multicolumn{9}{|l|}{ Index insulin source, n (\%) } \\
\hline Human insulin & $6,494(50.6)$ & $6,053(53.2)$ & I (reference) & & & I (reference) & & \\
\hline Insulin analog & $5,445(42.5)$ & $4,016(35.3)$ & 0.84 & $0.8 \mathrm{I}-0.87$ & $<0.001$ & 0.88 & $0.85-0.92$ & $<0.001$ \\
\hline Animal-derived insulin & $884(6.9)$ & $\mathrm{I}, 300(\mathrm{II} .4)$ & 1.27 & I.19-1.34 & $<0.001$ & 1.01 & $0.89-1.16$ & 0.860 \\
\hline \multicolumn{9}{|l|}{ Index insulin action profile, $\mathrm{n}(\%)$} \\
\hline Prandial insulin & $1,099(8.6)$ & $1,529(13.4)$ & 1.31 & $1.24-1.38$ & $<0.001$ & 1.24 & $1.09-1.40$ & 0.001 \\
\hline Basal insulin & $1,612(12.6)$ & $\mathrm{I}, 253(\mathrm{II} .0)$ & 0.92 & $0.87-0.98$ & 0.010 & 0.98 & $0.92-1.05$ & 0.539 \\
\hline Premixed insulin & $10,112(78.9)$ & $8,587(75.5)$ & I (reference) & & & I (reference) & & \\
\hline Count of $A_{l c}$ tests, mean (SD) & $0.39(0.67)$ & $0.27(0.60)$ & 0.77 & $0.75-0.80$ & $<0.001$ & 0.81 & $0.78-0.84$ & $<0.001$ \\
\hline Any claims-based hypoglycemia events, n (\%) & $79(0.6)$ & $122(1.1)$ & 1.50 & $1.26-1.80$ & $<0.001$ & $\mathrm{I} .44$ & $1.20-1.74$ & $<0.001$ \\
\hline \multicolumn{9}{|l|}{ Comorbidities and complications } \\
\hline $\mathrm{CCl}$, mean $(\mathrm{SD})$ & $1.79(1.34)$ & $2.19(1.52)$ & 1.13 & $1.12-1.14$ & $<0.001$ & 1.01 & $0.99-1.02$ & 0.228 \\
\hline Hypertension, n (\%) & $5,063(39.5)$ & $6,976(61.4)$ & 1.97 & $1.90-2.05$ & $<0.001$ & 1.80 & $1.71-1.88$ & $<0.001$ \\
\hline Dyslipidemia, n (\%) & $2,750(21.4)$ & $3,590(31.6)$ & $\mathrm{I} .48$ & I.43-I.54 & $<0.001$ & 1.19 & $1.14-1.25$ & $<0.001$ \\
\hline Retinopathy, n (\%) & $2,156(16.8)$ & $\mathrm{I}, 90 \mathrm{I}(16.7)$ & 1.00 & $0.95-1.05$ & 0.985 & 1.04 & $0.99-1.10$ & 0.142 \\
\hline Neuropathy, n (\%) & $3,483(27.2)$ & $2,096(18.4)$ & 0.68 & $0.65-0.7$ I & $<0.001$ & 0.81 & $0.77-0.85$ & $<0.001$ \\
\hline Nephropathy, n (\%) & $2,616(20.4)$ & I,55I (I3.6) & 0.69 & $0.65-0.72$ & $<0.001$ & 0.77 & $0.73-0.82$ & $<0.001$ \\
\hline Count of unique $\mathrm{OAD}$ drug classes, mean (SD) & $2.38(1.29)$ & $2.05(1.28)$ & 0.86 & $0.85-0.87$ & $<0.001$ & 0.86 & $0.84-0.87$ & $<0.001$ \\
\hline Any hospitalizations, n (\%) & $2,824(22.0)$ & $2,653(23.3)$ & 0.98 & $0.94-1.03$ & 0.455 & 0.64 & $0.60-0.68$ & $<0.001$ \\
\hline Direct medical cost $(\$)$, mean (SD) & $798(1,456)$ & $898(1,532)$ & 1.14 & $1.12-1.16$ & $<0.001$ & 1.16 & $1.14-1.18$ & $<0.001$ \\
\hline
\end{tabular}

Note: HR > I indicates that patients were less likely to be persistent than the reference group.

Abbreviations: SD, standard deviation; $\mathrm{HR}$, hazard ratio; $\mathrm{Cl}$, confidence interval; $\mathrm{CCl}$, Charlson Comorbidity Index; OAD, oral antidiabetic medication.

Middle-aged patients may develop more dependency on medication therapy than young patients considering their health status, which may lead to higher adherence/persistence. Patients $>70$ years are likely to have more difficulties on adherence/persistence to their medicine than younger patients due to their complex treatment regimens (including drugs for other comorbidities). Considering that patients with earlyonset disease may incur the greatest economic burden to the health care system, the poorest adherence among younger patients may warrant closer attention from the public. We did not find any gender differences in adherence, but we did find that women had a lower probability of being persistent than men for insulin therapy, which is consistent with results from other countries from previous studies. ${ }^{17,39}$

Previous studies have found that patients initiated with analog insulin may have higher likelihood of being adherent and persistent relative to patients initiated with human insulin, this is due to its improved physiologic time-action profiles, lower risk of hypoglycemia, and greater flexibility in dosing. ${ }^{17,35,38,40,41}$ Our study confirmed this finding among Chinese users in both insulin adherence and persistence. Also of note, $9 \%$ of insulin users in our study cohort initiated insulin therapy with animal-derived insulin, and these patients had a much lower adherence rate than those initiated with human insulin.

Almost $80 \%$ of the insulin-naïve patients with T2D initiated with premixed insulin in our study, different from countries where more patients initiated therapy with basal insulin (such as the US) ${ }^{42}$ Premixed insulin is also found to be associated with a better adherence than basal insulin. Diabetic patients in China are usually diagnosed and initiated insulin therapy at a later stage, and so pancreatic $\beta$-cell dysfunction and reduction of early-phase insulin spike are seen sooner and are more severe compared with Caucasians. This can cause more significant postprandial hyperglycemia, leading to further deterioration owing to the traditional 
carbohydrate-rich Chinese diet. ${ }^{43}$ This may explain the higher adherence/persistence rate among the premixed users as it may provide better overall glycemic control. The lower acquisition costs of premixed insulin than basal insulin may also be a reason. Our unadjusted analyses (Table 2) also found that patients using pen devices showed higher insulin adherence/persistence compared with patients using vial/ syringe. Previous studies reported that insulin pens could increase the convenience of insulin delivery and decrease injection pain and have positive effects on patient preference and adherence. ${ }^{14,44}$ However, administration mode was not included in the multivariate analysis due to collinearity.

Patients who had a higher baseline count of OAD classes, more baseline $\mathrm{HbA}_{1 \mathrm{c}}$ tests, and presence of microvascular complications including neuropathy and nephropathy were more likely to be adherent and persistent to their insulin therapy. These patients probably had longer disease duration and had failed previous treatments, suggesting that disease severity plays a role in adherence to insulin. The positive association between $\mathrm{HbA}_{1 \mathrm{c}}$ test frequency and adherence/ persistence indicated the importance of glucose monitoring in changing patients' behavior in drug use and treatment outcome. This could also be due to the fact that patients checking $\mathrm{HbA}_{1 \mathrm{c}}$ more frequently may pay more attention to their health status and be more likely to be adherent to medication therapy. Besides, presence of comorbidities including hypertension and dyslipidemia was associated with poorer adherence/persistence, as multidrug regimens were a factor frequently reported by patients with T2D as leading to insulin omissions. ${ }^{45}$ Baseline claims-based hypoglycemic events were negatively associated with adherence and persistence, although only $0.8 \%$ of the study cohort had baseline hypoglycemic events in our study.

\section{Limitations}

Our study had some limitations. First, the analyses were based on data from an insured population in employment or those who had retired and may not be representative of other populations in China. Second, estimates of both adherence and persistence in this study were based on patterns of drugs dispensed, but not necessarily consumed. Third, since the dispensed quantity and strength in inpatients claims are unavailable in the UEBMI database, our analysis treated the days during a diabetes-related hospitalization with $\geq 1$ prescriptions of insulin as days with insulin supply with an assumption that patients are always adherent to their treatment during a hospitalization, which may lead to upward bias. As the mean annual length of stay among insulin-naïve patients with T2D is relatively short (around 8 days), this bias may be small. Finally, patients who received more than one type of insulin were excluded from our study when considering for patient homogeneity and convenience for statistical analyses. This is also consistent with the Chinese clinical guideline which recommends monotherapy for the initial insulin treatment. Further research may be warranted regarding this patient group.

\section{Conclusion}

In a cohort of Chinese patients with T2D who were newly initiating insulin, poor adherence and persistence were prevalent. Adherence/persistence was higher for patients initiating with insulin analog or premixed insulin. Predictors of poor adherence/persistence with insulin included being elderly ( $\geq 70$ years), baseline claims-based hypoglycemic events, and presence of hypertension or dyslipidemia. Patients who had higher count of baseline $\mathrm{HbA}_{1 \mathrm{c}}$ tests, higher count of baseline OAD classes, and presence of microvascular complications, including neuropathy and nephropathy, were more likely to be adherent and persistent to their insulin treatment. Further research should examine whether higher insulin adherence and persistence translate into better long-term clinical and economic outcomes in the real world.

\section{Acknowledgment}

This study was supported by Eli Lilly and Company.

\section{Disclosure}

KW and HW are employees of Eli Lilly and Company. The authors report no other conflicts of interest in this work.

\section{References}

1. International Diabetes Federation. Diabetes Atlas. 7th ed. Brussels, Belgium: International Diabetes Federation; 2015. Available from: http:// www.diabetesatlas.org/. Accessed August 14, 2016.

2. Guariguata L, Whiting DR, Hambleton I, Beagley J, Linnenkamp U, Shaw JE. Global estimates of diabetes prevalence for 2013 and projections for 2035. Diabetes Res Clin Pract. 2014;103(2):137-149.

3. China Guideline for Type 2 Diabetes (2013 version). Chin J Diabetes. 2014;08:2-42.

4. Centers for Disease Control and Prevention. 2014 National Diabetes Statistics Report. Available from: http://www.cdc.gov/diabetes/data/ statistics/2014StatisticsReport.html. Accessed August 31, 2015.

5. American Diabetes Association. Diagnosis and classification of diabetes mellitus. Diabetes Care. 2013;36(Suppl 1):S67-S74.

6. Kumar V, Abbas AK, Fausto N, Robbins SL, Cotran RS. Robbins and Cotran Pathologic Basis of Disease. Philadelphia, PA: Elsevier Saunders; 2005.

7. Holman RR, Paul SK, Bethel MA, Matthews DR, Neil HA. 10-Year follow-up of intensive glucose control in type 2 diabetes. N Engl J Med. 2008;359:1577-1589.

8. Stratton IM, Adler AI, Neil HA, et al. Association of glycaemia with macrovascular and microvascular complications of type 2 diabetes (UKPDS 35): prospective observational study. Br Med J. 2000;321:405-412.

9. American Diabetes Association. Standards of medical care in diabetes. Diabetes Care. 2012;35:S11-S63. 
10. NICE. Type 2 diabetes. National Clinical Guideline for Management in Primary and Secondary Care (update). London, UK: National Institute for Health and Clinical Excellence; 2008.

11. Nathan DM, Buse JB, Davidson MB, et al. Medical management of hyperglycemia in type 2 diabetes: a consensus algorithm for the initiation and adjustment of therapy: a consensus statement of the American Diabetes Association and the European Association for the Study of Diabetes. Diabetes Care. 2009;32:193-203.

12. Chinese Diabetes Society. China Guideline for Type 2 Diabetes (2010 version). Available from: http://www.diab.net.cn/uploadfile/ueditor/file/ 20160811/6360650768334000005174021.pdf. Accessed November 23, 2016.

13. Pan C, Yang W, Jia W, Weng J, Tian H. Management of Chinese patients with type 2 diabetes, 1998-2006: the Diabcare-China surveys. Curr Med Res Opin. 2009;25(1):39-45.

14. Baser O, Bouchard J, DeLuzio T, Henk H, Aagren M. Assessment of adherence and healthcare costs of insulin device $\left(\right.$ FlexPen $\left.^{\circledR}\right)$ versus conventional vial/syringe. Adv Ther. 2010;27(2):94-104.

15. Cramer JA, Roy A, Burrell A, et al. Medication compliance and persistence: terminology and definitions. Value Health. 2008;11:44-47.

16. Egede LE, Gebregziabher M, Hunt KJ, et al. Regional, geographic, and ethnic differences in medication adherence among adults with type 2 diabetes. Ann Pharmacother. 2011;45(2):169-178.

17. Bonafede MM, Kalsekar A, Pawaskar M, et al. A retrospective database analysis of insulin use patterns in insulin-naïve patients with type 2 diabetes initiating basal insulin or mixtures. Patient Prefer Adherence. 2010;4:147-156.

18. Buysman E, Conner C, Aagren M, Bouchard J, Liu F. Adherence and persistence to a regimen of basal insulin in a pre-filled pen compared to vial/syringe in insulin-naïve patients with type 2 diabetes. Curr Med Res Opin. 2011;27:1709-1717.

19. Ascher-Svanum H, Lage MJ, Perez-Nieves M, et al. Early discontinuation and restart of insulin in the treatment of type 2 diabetes mellitus. Diabetes Ther. 2014;5:225-242

20. Cramer JA. A systematic review of adherence with medications for diabetes. Diabetes Care. 2004;27:1218-1224.

21. Davies MJ, Gagliardino JJ, Gray LJ, Khunti K, Mohan V, Hughes R. Real-world factors affecting adherence to insulin therapy in patients with type 1 or type 2 diabetes mellitus: a systematic review. Diabet Med. 2013;30(5):512-524.

22. Wei W, Pan C, Xie L, Baser O. Real-world insulin treatment persistence among patients with type 2 diabetes. Endocr Pract. 2014;20(1): $52-61$.

23. Cao MM, Dong NW. Interpretation of Chinese Society of Endocrinology (2010) consensus statement on $\mathrm{HbHbA1c}$ control target in adults with type 2 diabetes in China (in Chinese). Chinese J Pract Internal Med. 2011;31(2):113-115.

24. Lin $X$, Huang $X$, Chen $L$. The insulin adherence and nursing intervention among T2D patients and the Chinese (in Chinese). Prim Health Care. 2011;25:92-93.

25. Wang A, Zhang Z . The adherence and intervention among T2D patients initiated with intensifying insulin therapy (in Chinese). P Clin Med. 2007:16:217-219.

26. Qin $\mathrm{H}, \mathrm{Lu} \mathrm{H}$. The insulin adherence among T2D patients after discharge (in Chinese). Internal Med China. 2012;7:669-670.

27. Tianjin Daily, May 9, 2012. Available from: http://www.gov.cn/ gzdt/2012-05/09/content_2132977.htm. Accessed August 31, 2015.

Patient Preference and Adherence

\section{Publish your work in this journal}

Patient Preference and Adherence is an international, peer-reviewed, open access journal that focuses on the growing importance of patient preference and adherence throughout the therapeutic continuum. Patient satisfaction, acceptability, quality of life, compliance, persistence and their role in developing new therapeutic modalities and compounds to optimize
28. Quan H, Sundararajan V, Halfon P, et al. Coding algorithms for defining comorbidities in ICD-9-CM and ICD-10 administrative data. Med Care. 2005;43:1130-1139.

29. Wang L, Wei W, Miao R, Xie L, Baser O. Real-world outcomes of US employees with type 2 diabetes mellitus treated with insulin glargine or neutral protamine Hagedorn insulin: a comparative retrospective database study. BMJ Open. 2013;3(4):1-9.

30. Van Wijk BL, Klungel OH, Heerdink ER, de Boer A. The association between compliance with antihypertensive drugs and modification of antihypertensive drug regimen. J Hypertens. 2004;22:1831-1837.

31. Li J, McCombs JS, Stimmel GL. Cost of treating bipolar disorder in the California Medicaid (Medi-Cal) program. J Affect Disord. 2002; 71:131-139.

32. Pawaskar M, Bonafede M, Johnson B, Fowler R, Lenhart G, Hoogwerf B. Medication utilization patterns among type 2 diabetes patients initiating Exenatide BID or insulin glargine: a retrospective database study. BMC Endocr Disord. 2013;13:20.

33. Bank of China. Foreign Exchange Rate. Available from: http://srh bankofchina.com/search/whpj/search.jsp. Accessed August 31, 2015.

34. Ogbera AO, Kuku SF. Insulin use, prescription patterns, regimens and costs.-a narrative from a developing country. Diabetol Metab Syndr. 2012;4(1):50.

35. Aziz KM. Management of type- 1 and type- 2 diabetes by insulin injections in diabetology clinics - a scientific research review. Recent Pat Endocr Metab Immune Drug Discov. 2012;6:148-170.

36. Chrvala CA, Sherr D, Lipman RD. Diabetes self-management education for adults with type 2 diabetes mellitus: a systematic review of the effect on glycemic control. Patient Educ Couns. 2016;99:926-943.

37. Peyrot M, Rubin RR. Factors associated with persistence and resumption of insulin pen use for patients with type 2 diabetes. Diabetes Technol Ther. 2011;13:43-48.

38. Cooke CE, Lee HY, Tong YP, Haines ST. Persistence with injectable antidiabetic agents in members with type 2 diabetes in a commercial managed care organization. Curr Med Res Opin. 2010;26:231-238.

39. Hertz RP, Unger AN, Lustik MB. Adherence with pharmacotherapy for type 2 diabetes: a retrospective cohort study of adults with employersponsored health insurance. Clin Ther. 2005;27:1064-1073.

40. Bonafede MM, Kalsekar A, Pawaskar M, et al. Insulin use and persistence in patients with type 2 diabetes adding mealtime insulin to a basal regimen: a retrospective database analysis. BMC Endocr Disord. 2011;11:3.

41. Barag SH. Insulin therapy for management of type 2 diabetes mellitus: strategies for initiation and long-term patient adherence. J Am Osteopath Assoc. 2011;111(7 Suppl 5):S13-S19.

42. Baser O, Tangirala K, Wei W, Xie L. Real-world outcomes of initiating insulin glargine-based treatment versus premixed analog insulins among US patients with type 2 diabetes failing oral antidiabetic drugs. Clinicoecon Outcomes Res. 2013;3(5):497-505.

43. Yang J, Li J. Premixed or basal insulin: the insulin initiation consideration in Chinese patients with type2 diabetes mellitus. Chin J Endocrinol Metab. 2013;29:1-5

44. Lee WC, Balu S, Cobden D, et al. Medication adherence and the associated health-economic impact among patients with type 2 diabetes mellitus converting to insulin pen therapy: an analysis of third-party managed care claims data. Clin Ther. 2006;28:1712-1725.

45. Farsaei S, Radfar M, Heydari Z, Abbasi F, Qorbani M. Insulin adherence in patients with diabetes: risk factors for injection omission. Prim Care Diabetes. 2014;8:338-345. 